\title{
BMJ Open How do adults with physical disability experience primary care? A nationwide cross-sectional survey of access among patients in England
}

To cite: Popplewell NTA, Rechel BPD, Abel GA. How do adults with physical disability experience primary care? A nationwide crosssectional survey of access among patients in England. BMJ Open 2014;4:e004714. doi:10.1136/bmjopen-2013004714

- Prepublication history and additional material is available. To view please visit the journal (http://dx.doi.org/ 10.1136/bmjopen-2013004714).

Received 18 December 2013 Accepted 6 June 2014

\section{CrossMark}

${ }^{1}$ Cambridge Centre for Health Services Research, Department of Public Health and Primary Care, University of Cambridge, Cambridge, UK ${ }^{2}$ Department of Disease Control, London School of Hygiene \& Tropical Medicine, London, UK

${ }^{3}$ School of Public Health Research, Institute of Public Health, University of Cambridge, Cambridge, UK

Correspondence to Dr Nicola Popplewell; n.popplewell@ntlworld.com

\section{ABSTRACT}

Objectives: Almost a quarter of adults in England report a longstanding condition limiting physical activities. However, recent overseas evidence suggests poorer access to healthcare for disabled people. This study aimed to compare patient-reported access to English primary care for adults with and without physical disability.

Design: Secondary analysis of the 2010/11 General Practice Patient Survey (response rate $35.9 \%$ ) using logistic regression.

Setting and participants: 1780977 patients, from 8384 English general practices, who provided information on longstanding conditions limiting basic physical activity. 41389 of these patients reported unmet need to see a doctor in the previous 6 months.

Outcomes: Difficulty getting to the general practitioner (GP) surgery as a reason for unmet need to see a doctor in the preceding 6 months; difficulty getting into the surgery building

Results: Estimated prevalence of physical disability was $17.2 \%$ (95\% Cl $17.0 \%$ to $17.3 \%$ ). $17.9 \%$ (95\% Cl $17.4 \%$ to $18.4 \%$ ) of patients with an unmet need to see a doctor were estimated to experience this due to difficulty getting to the surgery, and $2.2 \%(95 \% \mathrm{Cl}$ $2.2 \%$ to $2.3 \%$ ) of all patients registered with a GP were estimated to experience difficulty getting into surgery buildings. Adjusting for gender, age, health status and employment, difficulty getting to the surgery explaining unmet need was more likely for patients with physical disability than for those without. Similarly, difficulty getting into surgery buildings was more likely among physically disabled patients. Both associations were stronger among patients aged 65-84 years.

Conclusions: Adults in England with physical disability experience worse physical access into primary care buildings than those without. Physical disability is also associated with increased unmet healthcare need due to difficulty getting to GP premises, compared with the experience of adults without physical disability. Increasing age further exacerbates these problems. Access to primary care in England for patients with physical disability needs improving.

\section{Strengths and limitations of this study}

- The study provides recent evidence relevant to the UK on associations between physical disability and access to and into primary care in England.

- The study obtained wide, national coverage across England using a very large sample and a sampling technique maximising representativeness and generalisability to the adult population of England who are registered with a general practitioner (GP), and allowing precise population estimates.

- The survey instrument (the General Practice Patient Survey (GPPS)) was tested thoroughly and steps were taken to maximise response and minimise error and information bias.

- The $36 \%$ response rate for the GPPS and item non-response leading to exclusion from analysis has the potential to introduce selection bias. If present, such bias would most likely lead to underestimated associations between physical disability and physical access to and into GP surgeries.

- Measurement error is also possible: physical disability is difficult to measure in surveys, and the validity of the method used to determine unmet need to see a doctor could not be tested using this dataset.

\section{INTRODUCTION}

Physical disability is a major global concern, ${ }^{1}$ and represents the commonest form of disability in Great Britain ${ }^{2}$ : during 2009, 22\% of men and $23 \%$ of women in the UK reported a longstanding condition that limited activities. ${ }^{3}$ Such disabilities can cause increased morbidity, mortality and healthcare need. ${ }^{145}$

Consequently, the WHO emphasises that people with disabilities require access to healthcare and recommends their needs be met by primary healthcare, with specialist referral where necessary. ${ }^{1}$ However, such 
access is influenced by interactions between a person's impairment and their physical and social environments, so that individuals can experience limited access to preventive care, diagnosis and treatment. ${ }^{1}{ }^{5-9}$ Therefore, higher unmet health need exists among people with disability than among people without (World Health Survey 2002-2004). ${ }^{1}$ Specific problems in accessing primary care include 'physical, attitudinal, expertiserelated and systemic' barriers experienced when 'finding a doctor, getting an appointment, entering and using the facilities, and obtaining quality care'. ${ }^{6}$ Such problems can worsen with increasing age, ${ }^{10}{ }^{11}$ and can also result in delayed presentation, worse prognosis and further increased need. ${ }^{12}{ }^{13}$ Therefore, ensuring rights of access to healthcare for people with disabilities is important: the 2008 United Nations Convention on the Rights of Persons with Disabilities sought to ensure such access, ${ }^{14}$ and international consensus among health and disability experts has concluded that investigating barriers experienced by people with disability when accessing healthcare remains a top priority. ${ }^{15}$

In the UK, the Convention on the Rights of Persons with Disabilities has been ratified and the Equality Act 2010 passed, ${ }^{16}$ such that reasonable accessibility to primary care and transport services are expected. However, although almost all adults in England have access to primary care via registration with a National Health Service (NHS) general practitioner (GP), limited recent empirical evidence exists regarding patient experience of general practice accessibility among physically disabled patients. ${ }^{17} 18$ An analysis of the Life Opportunities Survey has shown that individuals with chronic health conditions or impairments were more likely to report a range of issues with access to healthcare, from being able to get to appointments and getting into buildings, to lack of help with communication. ${ }^{18}$ In light of this paucity of evidence, this study seeks to add to the predominantly North American literature on this subject using data from the 2010/11 nationwide General Practice Patient Survey (GPPS), which is used by the Department of Health in England to assess patient experience of primary care. ${ }^{19}$

This study explores whether adult patients with physical disability, registered with English GPs, experience difficulty accessing primary care compared with patients without such disability. In particular, we assess experience of inability to get to the surgery as a reason for unmet need to see a doctor in the preceding 6 months, and inability to get into the surgery building.

\section{METHODS}

\section{Study design and General Practice Patient Survey}

This study was a secondary analysis of 2010/11 GPPS data obtained using a nationwide, cross-sectional survey, sampling from adults registered with an English NHS GP. $^{20}$ Details of questionnaire development, ${ }^{20-22}$ and the questionnaires themselves are available elsewhere, as are eligibility criteria and sample size calculation for the GPPS. $^{20}$ A total of 8397 practices with eligible patients were identified and patients stratified by practice, age-band, then gender, before 5561368 patients were selected systematically on a ' 1 in n' basis. ${ }^{20}$ Small practices and those with known low response rates were oversampled. Full details are published elsewhere ${ }^{20}$ : 1994410 responses were received (GPPS response rate $35.9 \%)$.

\section{Study samples}

Associations between physical disability and access into surgery buildings were assessed in a sample of 1780977 GPPS respondents who were sent a questionnaire and answered the survey question 'Do you have any of the following long-standing conditions? 20 (response rate for this item $32.0 \%$ ). Respondents could report up to six categories of condition, including 'a condition that substantially limits one or more basic physical activities, such as walking, climbing stairs, lifting or carrying', thus providing information on the presence of a physical disability. They could also confirm they had no such conditions.

Associations between physical disability and difficulty getting to the surgery as a reason for unmet need to see a doctor were assessed in a sub-sample of 41389 patients who provided information on longstanding conditions and indicated an unmet need to see a doctor in the previous 6 months on the GPPS. ${ }^{20}$ Respondents with missing data for when they last saw a doctor $(n=48090)$ or why they had not seen a doctor $(n=8976)$ were not included in the sub-sample.

\section{Study observations}

Respondents who ticked 'I couldn't get to the GP surgery or health centre easily' in response to 'If you haven't seen a doctor in the past 6 months, why is that?' were classed as having difficulty getting to the surgery (four other possible reasons were allowed, with respondents invited to tick all that apply).$^{20}$ Ease of access into the surgery was assessed using 'How easy do you find it to get into the building at your GP surgery or health centre?'. Responses of 'Not very easy' or 'Not at all easy' were defined as 'Difficulty', and 'Very easy' or 'Fairly easy' as 'No difficulty'.

Gender; age group (8 categories); employment status (8 categories); self-reported health status ( 5 ordinal categories); presence or absence of each of five other longstanding conditions (deafness/severe hearing impairment; blindness/severe visual impairment; learning difficulty; psychological/emotional condition; other) and ethnic group (combined from 16 Office for National Statistics categories ${ }^{23}$ into 6) were identified from GPPS responses. Four categories of rurality ${ }^{24}$ and population-based quintiles of the 2007 Lower Super-Output Area Indices of Multiple Deprivation ${ }^{25}$ were determined from the patient's postcode of residence. Mode of survey completion and patient-level 
weights accounting for survey design and non-response, derived by the survey provider, were also in the dataset. $^{20}$

\section{Statistical analyses}

The percentages of the population that report physical disability and study outcomes were calculated using weights, thereby accounting for sampling procedures and survey non-response by age, gender and practice. All other analyses were un-weighted. Initial un-weighted analyses used only data that were complete for all variables in table 1, though final analyses reported here only excluded observations with missing age, gender, employment, health status or outcome data.

Results for both outcomes were obtained using univariable and multivariable logistic regression, using population-averaged, generalised estimating equations with exchangeable correlation matrices and robust SEs, thereby accounting for correlation of observations by practice and assessing patient-level associations across England. Combined Wald tests were used for hypothesis tests. In the adjusted models, age and gender were considered a priori confounders. All other covariates were added to the models in sequence, based on their effects on the associations of interest in preliminary analyses, and remained if the OR altered compared to the unadjusted model. An interaction term was added to the final models to assess whether associations between physical disability and outcomes varied with age group.

All analyses were completed using Stata MP V.11.2.

\section{RESULTS}

\section{Participants}

Figure 1 shows the flow of patients for the GPPS and those eligible for this study: 8384 practices were represented in the larger sample and 7738 in the sub-sample. Un-weighted sample descriptions by physical disability are shown in table 1 . The main sample for un-weighted analysis comprised 1634853 observations (21.5\% with physical disability) from 8380 practices (146 124 eligible observations excluded due to missing covariate and outcome data). In all, 38468 observations (29.3\% with physical disability) from 7658 practices were available for analysis of the sub-sample after similarly excluding 2921 observations.

Over half of the respondents in both study samples were women. Similarly, the majority of those in the main sample were aged 55 years or over. The commonest reported employment was full-time work (35.6\% of main sample; $42.2 \%$ of sub-sample) and self-reported health status was predominantly good (35.5\% of main sample; $33.0 \%$ of sub-sample). Deprivation scores were reasonably spread throughout deprivation groups, though the greatest proportions of respondents were from more deprived areas.

Table 1 also shows that patients in both samples with physical disability were more likely than those without to be white, aged 55 years or over, retired, from more deprived areas, and have only fair or poor health, and any other longstanding condition. Patients with unmet health need who also reported physical disability were more likely to be women.

\section{Estimated prevalence}

The estimated percentage of patients with physical disability in the population (calculated using non-response and design weights) was $17.2 \%$ (95\% CI $17.0 \%$ to $17.3 \%)$ among adults registered with a GP in England and $23.8 \%$ (95\% CI $23.3 \%$ to $24.3 \%$ ) in those with an unmet need to see a doctor. Similarly, population estimates based on weighted analyses suggest that $17.9 \%$ (95\% CI $17.4 \%$ to $18.4 \%$ ) of patients with an unmet need would cite difficulty getting to the surgery as a reason for that unmet need. This was substantially higher among patients with physical disability $(43.1 \%$; $95 \%$ CI $41.9 \%$ to $44.2 \%$ ) than non-disabled patients $(10.1 \%$; $95 \%$ CI $9.6 \%$ to $10.5 \%)$. Also we estimate that $2.2 \%$ (95\% CI $2.2 \%$ to $2.3 \%$ ) of the adult population had difficulty getting into surgery premises. Again this was higher among patients with physical disability (4.9\%; $95 \%$ CI $4.8 \%$ to $5.0 \%$ ) than non-disabled patients (1.7\%; $95 \%$ CI $1.6 \%$ to $1.7 \%)$.

\section{Associations between physical disability and access to surgeries}

Unadjusted and adjusted associations derived from regression analyses are shown in table 2. There was strong evidence for interactions between physical disability and age group (Wald tests $\mathrm{p}<0.001$ ), so adjusted associations are shown by age group. These analyses showed that difficulty getting to the surgery as a reason for unmet need to see a doctor in the previous 6 months was associated with physical disability after adjusting for gender, age, health status and employment. The strength of association between physical disability and difficulty getting to the surgery among these patients increased with age until aged 65-74 years $(\mathrm{OR}=3.94$; 95\% CI 3.22 to $4.81, \mathrm{p}<0.001)$, but was reduced among patients aged 85 or over (OR=1.49; 95\% CI 1.21 to 1.83 , $\mathrm{p}<0.001)$. No evidence was found of an association for age groups less than 45 years (see table 2 ).

Strong evidence for an association between physical disability and difficulty getting into surgeries also existed, which remained after adjusting for the same covariates. For this outcome, evidence for such an association existed for all age groups, though the association was weakest among patients aged 35-44 years $(\mathrm{OR}=1.11$; $95 \%$ CI 1.02 to $1.21, \mathrm{p}=0.012)$, before reaching its greatest strength in the 75-84 years age group ( $\mathrm{OR}=2.39 ; 95 \%$ CI 2.23 to $2.55, \mathrm{p}<0.001)$.

\section{DISCUSSION}

Physical disability is common in the English population (in this study, estimated prevalence $17.2 \%$, rising to 
Table 1 Characteristics of respondents by physical disability, for the analysed samples*

\begin{tabular}{|c|c|c|c|c|c|c|c|c|}
\hline & \multicolumn{4}{|c|}{$\begin{array}{l}\text { Main study sample } \\
n=1634853\end{array}$} & \multicolumn{4}{|c|}{$\begin{array}{l}\text { Sub-sample with unmet } \\
\text { need to see a doctor } \\
n=38468\end{array}$} \\
\hline & \multicolumn{2}{|c|}{$\begin{array}{l}\text { Physical } \\
\text { disability } \\
n=351526(\% \dagger)\end{array}$} & \multicolumn{2}{|c|}{$\begin{array}{l}\text { No physical } \\
\text { disability } \\
n=1283327(\% \dagger)\end{array}$} & \multicolumn{2}{|c|}{$\begin{array}{l}\text { Physical } \\
\text { disability } \\
n=11283(\%+)\end{array}$} & \multicolumn{2}{|c|}{$\begin{array}{l}\text { No physical } \\
\text { disability } \\
n=27185(\% \dagger)\end{array}$} \\
\hline & & & & & & & & \\
\hline Maleł & 157019 & $(44.7)$ & 554422 & $(43.2)$ & 4285 & $(38.0)$ & 13213 & $(48.6)$ \\
\hline \multicolumn{9}{|l|}{ Age $(\text { years })^{*}$} \\
\hline $18-24$ & 2691 & $(0.8)$ & 71817 & (5.6) & 132 & (1.2) & 2269 & (8.4) \\
\hline $25-24$ & 7691 & (2.2) & 167918 & (13.1) & 302 & $(2.7)$ & 5106 & $(18.8)$ \\
\hline $35-44$ & 18649 & (5.3) & 222772 & (17.4) & 571 & (5.1) & 5944 & (21.9) \\
\hline $45-54$ & 41042 & $(11.7)$ & 257128 & (20.0) & 1148 & $(10.2)$ & 6277 & (23.1) \\
\hline $55-64 \ddagger$ & 78930 & (22.5) & 268128 & (20.9) & 1817 & $(16.1)$ & 4509 & (16.6) \\
\hline $65-74$ & 91298 & (26.0) & 192063 & (15.0) & 1747 & (15.5) & 1787 & $(6.6)$ \\
\hline $75-84$ & 80809 & (23.0) & 86959 & $(6.8)$ & 2478 & (22.0) & 845 & (3.1) \\
\hline 85 or over & 30416 & $(8.7)$ & 16542 & (1.3) & 3088 & $(27.4)$ & 448 & (1.7) \\
\hline \multicolumn{9}{|l|}{ Employment ${ }^{\star}$} \\
\hline Full-time work $\ddagger$ & 37305 & $(10.6)$ & 544202 & $(42.4)$ & 1123 & $(10.0)$ & 15099 & $(55.5)$ \\
\hline Part-time work & 19607 & $(5.6)$ & 195281 & (15.2) & 427 & (3.8) & 3361 & (12.4) \\
\hline Full-time education & 1183 & (0.3) & 29297 & (2.3) & 53 & $(0.5)$ & 965 & (3.6) \\
\hline Unemployed & 12497 & (3.6) & 57576 & (4.5) & 307 & (2.7) & 1434 & (5.3) \\
\hline Permanently sick/disabled & 73016 & $(20.8)$ & 24719 & (1.9) & 3591 & $(31.8)$ & 858 & (3.2) \\
\hline Retired & 184616 & $(52.5)$ & 313383 & (24.4) & 5167 & $(45.8)$ & 3160 & $(11.6)$ \\
\hline Looking after home & 18370 & $(5.2)$ & 87044 & $(6.8)$ & 397 & $(3.5)$ & 1333 & $(4.9)$ \\
\hline Something else & 4932 & (1.4) & 31825 & (2.5) & 218 & (1.9) & 975 & (3.6) \\
\hline \multicolumn{9}{|l|}{ Health status* } \\
\hline Excellent & 2939 & $(0.8)$ & 138724 & $(10.8)$ & 53 & $(0.5)$ & 2246 & (8.3) \\
\hline Very good & 22236 & (6.3) & 455991 & $(35.5)$ & 406 & (3.6) & 7684 & $(28.3)$ \\
\hline Good $\ddagger$ & 87631 & (24.9) & 493157 & (38.4) & 1745 & $(15.5)$ & 10947 & (40.3) \\
\hline Fair & 160144 & $(45.6)$ & 172142 & (13.4) & 4792 & $(42.5)$ & 5245 & (19.3) \\
\hline Poor & 78576 & (22.4) & 23313 & $(1.8)$ & 4287 & (38.0) & 1063 & (3.9) \\
\hline \multicolumn{9}{|l|}{ Deafness§ } \\
\hline Yes & 62550 & $(18.0)$ & 80352 & (6.3) & 2624 & (23.3) & 1270 & (4.7) \\
\hline \multicolumn{9}{|l|}{ Blindness§ } \\
\hline Yes & 17299 & (4.9) & 14459 & $(1.1)$ & 1287 & $(11.4)$ & 427 & (1.6) \\
\hline \multicolumn{9}{|l|}{ Psychological condition§ } \\
\hline Yes & 31841 & $(9.1)$ & 63033 & $(4.9)$ & 1058 & (9.4) & 1710 & (6.3) \\
\hline \multicolumn{9}{|l|}{ Learning difficulty§ } \\
\hline Yes & 8501 & (2.4) & 15145 & $(1.2)$ & 283 & (2.5) & 431 & (1.6) \\
\hline \multicolumn{9}{|l|}{ Other conditions§ } \\
\hline Yes & 125635 & (35.7) & 334734 & $(26.1)$ & 4516 & $(40.0)$ & 6970 & $(25.6)$ \\
\hline \multicolumn{9}{|l|}{ No longstanding conditions§ } \\
\hline Yes & 6405 & $(1.8)$ & 838324 & $(65.3)$ & 155 & (1.4) & 17717 & $(65.2)$ \\
\hline \multicolumn{9}{|l|}{ Rurality } \\
\hline Urban‡ & 305404 & $(86.9)$ & 1095041 & $(85.3)$ & 9904 & $(87.8)$ & 24433 & $(89.9)$ \\
\hline Town/fringe & 36746 & (10.5) & 145699 & (11.4) & 1121 & $(9.9)$ & 2282 & $(8.4)$ \\
\hline Village & 7871 & $(2.2)$ & 35780 & $(2.8)$ & 220 & (2.0) & 386 & (1.4) \\
\hline Hamlet/isolated & 1447 & $(0.4)$ & 6573 & $(0.5)$ & 38 & П) & 84 & | \\
\hline Missing & 58 & $(0.0)$ & 234 & $(0.0)$ & & & & \\
\hline IMD quintile ${ }^{\star \star}$ & & & & & & & & \\
\hline 1 (least deprived) & 45541 & $(13.0)$ & 243518 & $(19.0)$ & 1346 & $(11.9)$ & 3951 & $(14.5)$ \\
\hline 2 & 58233 & (16.6) & 253672 & (19.8) & 1833 & (16.3) & 4541 & (16.7) \\
\hline 3 & 66615 & (19.0) & 256456 & (20.0) & 2156 & (19.1) & 5222 & (19.2) \\
\hline 4 & 78685 & (22.4) & 262021 & (20.4) & 2565 & (22.7) & 6464 & (23.8) \\
\hline 5 (most deprived) $\ddagger$ & 102193 & (29.1) & 266592 & (20.8) & 3374 & (29.9) & 6983 & (26.0) \\
\hline Missing & 259 & $(0.1)$ & 1068 & $(0.1)$ & 9 & $(0.1)$ & 24 & $(0.1)$ \\
\hline Ethnicity & & & & & & & & \\
\hline Whitef & 316882 & $(90.1)$ & 1104565 & $(86.1)$ & 10328 & $(91.5)$ & 21393 & $(78.7)$ \\
\hline & & & & & & & & Continued \\
\hline
\end{tabular}


Table 1 Continued

\begin{tabular}{|c|c|c|c|c|c|c|c|c|}
\hline \multirow[b]{3}{*}{ Mixed } & \multicolumn{4}{|c|}{$\begin{array}{l}\text { Main study sample } \\
n=1634853\end{array}$} & \multicolumn{4}{|c|}{$\begin{array}{l}\text { Sub-sample with unmet } \\
\text { need to see a doctor } \\
n=38468\end{array}$} \\
\hline & \multicolumn{2}{|l|}{$\begin{array}{l}\text { Physical } \\
\text { disability } \\
n=351526(\%+)\end{array}$} & \multicolumn{2}{|c|}{$\begin{array}{l}\text { No physical } \\
\text { disability } \\
n=1283327 \text { (\%†) }\end{array}$} & \multicolumn{2}{|c|}{$\begin{array}{l}\text { Physical } \\
\text { disability } \\
n=11283(\% \dagger)\end{array}$} & \multicolumn{2}{|c|}{$\begin{array}{l}\text { No physical } \\
\text { disability } \\
\mathrm{n}=27185 \text { (\%†) }\end{array}$} \\
\hline & 1788 & $(0.5)$ & 11202 & $(0.8)$ & 66 & $(0.6)$ & 367 & $(1.4)$ \\
\hline Asian & 14712 & $(4.2)$ & 74715 & $(5.8)$ & 311 & $(2.8)$ & 2408 & (8.9) \\
\hline Black & 7301 & $(2.1)$ & 40939 & (3.2) & 205 & (1.8) & 1125 & $(4.1)$ \\
\hline Chinese & 622 & $(0.2)$ & 7451 & $(0.6)$ & 29 & $(0.3)$ & 347 & (1.3) \\
\hline Other & 6407 & (1.8) & 31313 & (2.4) & 193 & (1.7) & 1122 & $(4.1)$ \\
\hline Missing & 3814 & (1.1) & 13142 & (1.0) & 151 & (1.3) & 423 & (1.6) \\
\hline \multicolumn{9}{|l|}{ Collection mode $†$} \\
\hline Paper‡ & 343063 & (97.6) & 1218887 & $(95.0)$ & 10937 & (96.9) & 24993 & $(91.9)$ \\
\hline Telephone & 86 & $(0.0)$ & 63 & $(0.0)$ & 346 & 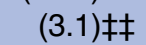 & 2192 & (8.1) $\ddagger \ddagger$ \\
\hline Online & 8377 & $(2.4)$ & 64377 & $(5.0)$ & & & & \\
\hline \multicolumn{9}{|l|}{ Difficulty getting to the surgery } \\
\hline Yes & Not applicable & Not ap & licable & & 5012 & $(44.4)$ & 2727 & $(10.0)$ \\
\hline \multicolumn{9}{|l|}{ Difficulty getting into GP building } \\
\hline Yes & 16534 & $(4.7)$ & 20473 & $(1.6)$ & \multicolumn{2}{|c|}{ Not applicable } & \multicolumn{2}{|c|}{ Not applicable } \\
\hline \multicolumn{9}{|c|}{ 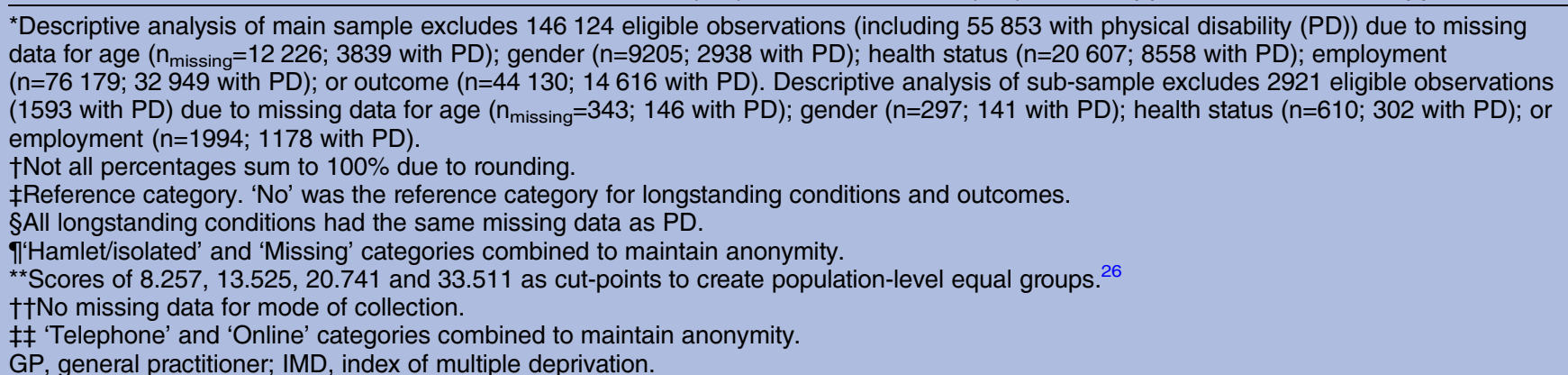 } \\
\hline
\end{tabular}

almost a quarter of those with unmet need to see a doctor). Among adult patients with physical disability who are registered with primary care in England, $43.1 \%$ are estimated to have unmet health need due to difficulty getting to the surgery, and $4.9 \%$ find difficulty entering their GP's building. Strong evidence existed for associations between physical disability and both difficulty getting to the surgery as a reason for unmet health need to see a doctor, and difficulty getting into surgery premises. These associations were modified by age, with physically disabled patients who were aged 65 years or over generally experiencing the most difficulty with access to and into their GP's premises.

The main strength of this study is the wide, national coverage obtained using a very large sample and a sampling technique that maximised representativeness and generalisability to the adult population of England who are registered with a GP. This further allowed precise population estimates. Additionally, the survey was tested thoroughly and steps taken to maximise response and minimise error and information bias. ${ }^{20-22}$ The main limitations are the low response rate for the GPPS and item non-response leading to exclusion from analysis. These potentially introduce selection bias. We suggest the most likely effect of such bias, if present, would be underestimated associations between physical disability and physical access to and into GP surgeries. This is because we consider that physically disabled patients may be under-represented, with their disability impairing ability to respond to the GPPS, particularly among those with more severe disability. It is also more likely that patients with the most severe disability experience the most difficulty accessing primary care, yet this would not be recorded if they did not respond. Similarly, item nonresponse to questions regarding difficulty accessing the surgery is also more likely among those with no difficulties, who are most likely to be the non-disabled patients. However, the magnitude of any such underestimate is difficult to predict. Furthermore, literature on survey methodology suggests that non-response bias is not inevitable when high non-response occurs, particularly in probability surveys, ${ }^{27}$ and is supported in analyses of other GPPS questions. ${ }^{26}$ Potential measurement error is another limitation: physical disability is difficult to measure, ${ }^{1}$ depending only on respondents' interpretations of the GPPS question regarding presence of a longstanding condition limiting basic physical activity that was used in past USA and Irish censuses. ${ }^{28} 29$ Any interpretation error here is most likely to have underestimated disability prevalence, and censuses are known to give lower estimates than disability surveys: ${ }^{129}$ prevalence of physical disability here was $5-6 \%$ lower than recent 


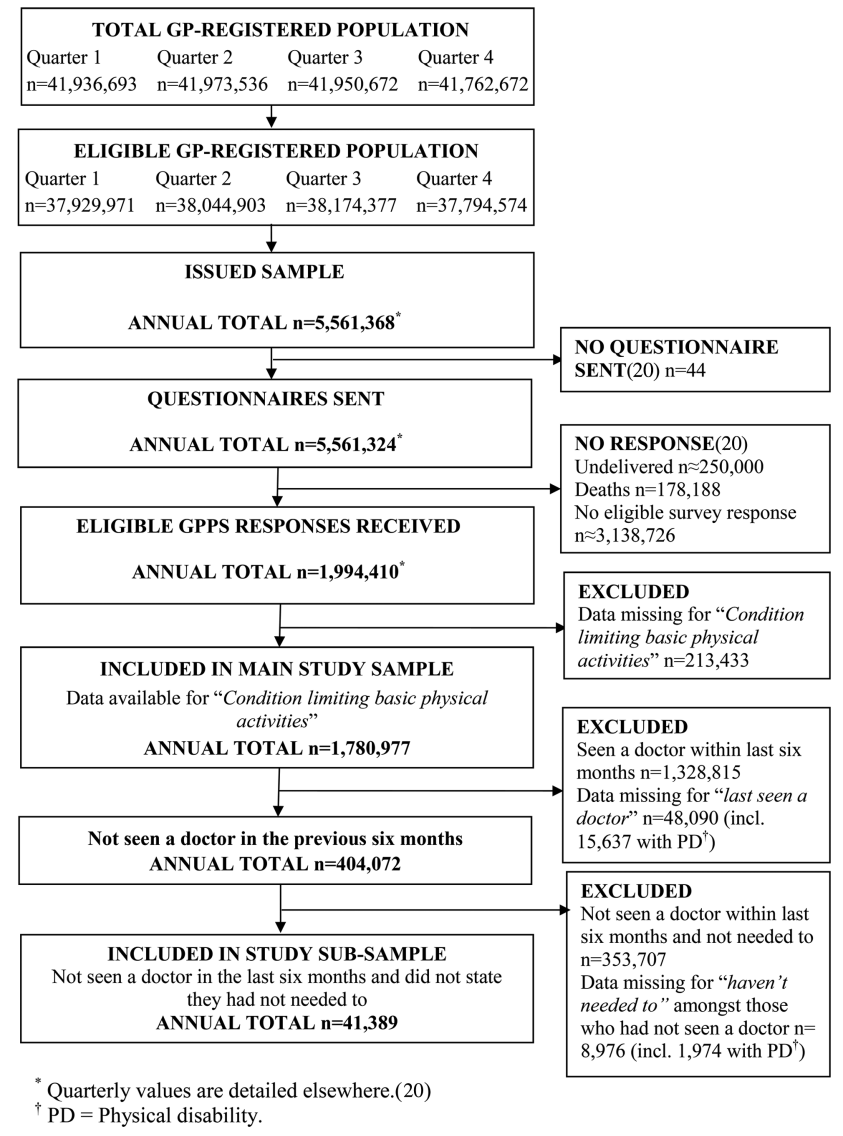

Figure 1 Flow diagram of data for the General Practice Patient Survey (GPPS) and samples used for this study (GP, general practitioner).

UK estimates that included all disability types. ${ }^{3}$ Similarly, unmet need to see a doctor was determined indirectly by inference from patients who had not seen a doctor in the preceding 6 months and their stated reasons why not (including that they had not needed to), rather than using a direct question regarding their unmet need: it was not possible to test the validity of this using the dataset. By its nature this study was limited to aspects of accessibility to healthcare that were asked about in the GPPS. We note that physical access is not limited to getting to and getting into premises and that accessibility of examining space and equipment are also important.

This study adds to existing literature in view of its size and English primary care setting, thus expanding and updating the predominantly North American evidence on the healthcare experience of disabled patients. It also focuses specifically on physical disability, rather than investigating all disability, potentially enabling clearer explanation of the associations found and identification of specific actions likely to benefit this patient group. It should be remembered, however, that problems of access are also an issue for those with learning disabilities and/or mental health problems. ${ }^{30}$

Our findings are consistent with the literature of various types from other countries that has generally found physical access to and into a variety of healthcare premises to be problematic for people with a range of disabilities, ${ }^{5-7} 911131730-34$ though evidence of compliance with American Disability Act design guidance and fewer problems is beginning to emerge in the USA. ${ }^{35}{ }^{36}$ With respect to the interaction between physical disability and age, others have also found increasing difficulties for older patients with disability: in high-income countries, the World Health Survey (2002-2004) found the highest prevalence of transport issues as a reason for unmet health need occurred in people with disability aged 60 years and over ${ }^{1}$ and satisfaction with access to care is worse for disabled patients aged over 65 years in the USA. $^{32}$ In this study, the observed association between physical disability and unmet need due to difficulty getting to the surgery weakened among the oldest disabled patients (aged 85 years and over). This finding is

Table 2 Associations between physical disability and difficulty getting to the surgery among patients with unmet health need, and between physical disability and difficulty getting into the surgery building: for each outcome results are derived from two logistic regression models (unadjusted and an adjusted model allowing the association to vary by age group)*

\begin{tabular}{|c|c|c|c|c|}
\hline & \multicolumn{2}{|c|}{$\begin{array}{l}\text { Unmet need due to difficulty getting to } \\
\text { surgery ( } n=38468)\end{array}$} & \multicolumn{2}{|c|}{ Difficulty getting into building ( $n=1634853)$} \\
\hline & OR (95\% Cl) & Wald test $p$ value & OR (95\% Cl) & Wald test $p$ value \\
\hline Unadjusted & $7.16(6.78$ to 7.56$)$ & $<0.001$ & 3.10 (3.02 to 3.17$)$ & $<0.001$ \\
\hline \multicolumn{5}{|c|}{ Adjusted for gender, health status and employment, by age (years) $\dagger$} \\
\hline $18-24$ & $1.04(0.62$ to 1.76$)$ & 0.874 & $1.74(1.45$ to 2.10$)$ & $<0.001$ \\
\hline $25-34$ & $0.99(0.70$ to 1.39$)$ & 0.951 & $1.25(1.11$ to 1.40$)$ & $<0.001$ \\
\hline $35-44$ & $1.11(0.88$ to 1.41$)$ & 0.387 & $1.11(1.02$ to 1.21$)$ & 0.012 \\
\hline $45-54$ & 1.39 (1.17 to 1.66$)$ & $<0.001$ & 1.36 (1.27 to 1.46$)$ & $<0.001$ \\
\hline $55-64$ & 2.03 (1.73 to 2.38$)$ & $<0.001$ & 1.46 (1.38 to 1.54$)$ & $<0.001$ \\
\hline $65-74$ & 3.94 (3.22 to 4.81$)$ & $<0.001$ & 1.97 (1.86 to 2.09$)$ & $<0.001$ \\
\hline $75-84$ & 3.22 (2.68 to 3.87$)$ & $<0.001$ & 2.39 (2.23 to 2.55$)$ & $<0.001$ \\
\hline 85 or over & 1.49 (1.21 to 1.83$)$ & $<0.001$ & 2.14 (1.97 to 2.34$)$ & $<0.001$ \\
\hline
\end{tabular}

${ }^{*}$ Full model outputs (including interaction terms allowing the association to vary by age group) are shown for both outcomes in online supplementary appendices A and B.

†Derived from a model including an interaction between physical disability and age group. For both outcomes, combined Wald tests for significance of interaction term had $p<0.001$. 
supported by a smaller study of accessibility of health services in Sao Paolo, Brazil among persons with various disabilities that also found a weaker association between disability and accessibility experience among patients aged 77 years or older than that for younger patients. ${ }^{34}$ Such a reduction in the strength of association among the eldest patients may be due to an increased willingness of these patients to ask for home visits and/or GPs' willingness to provide them. In contrast to our findings and those from the USA outlined above, Allen and Mor ${ }^{37}$ found that, among people with various disabilities, missed doctor's appointments due to unmet transport needs occurred more among working age adults than those aged 65 years and over in the USA. However, there was only weak evidence that age per se explained unmet transport needs in that study: greater poverty among younger respondents probably explained the difference. No studies specifically investigating the interaction between physical disability and age with respect to difficulty getting into healthcare premises were identified.

We consider that the associations we observed are most likely due to difficulty accessing useable and/or affordable transport, and problems with physical and architectural barriers at surgery premises (eg, heavy doors, absent or steep ramps), since these have been described as the main barriers to primary care by physically disabled American patients $^{9}$ and noted by many others. ${ }^{15} 7113338$ Lack of assistive devices and insufficient help from others have also been reported, ${ }^{6}{ }^{13} 37$ which could also explain our findings. We also believe that increased probability of difficulty getting to the surgery as a reason for unmet need for patients with physical disability and increasing age is due to worsening difficulties in accessing private and public transport experienced with aging. Patterns of transport use in the UK suggest reduced access to private transport over time among older people with physical difficulties ${ }^{39}$ and that the proportion of adults with mobility difficulties, age 70 years and over, reporting difficulty with travel to healthcare is greater than that for all adults with mobility difficulties. ${ }^{40}$ Finally, we believe that the probability of difficulty getting into buildings being reported may increase with age. We consider that this may occur if age-related worsening of co-ordination and strength exacerbates difficulties arising from the physical architecture that are already experienced by patients with other physical disability, and/or if increasing surgery usage with age highlights physical access problems, thus increasing the reporting of difficulties.

Potential consequences of these findings include adverse health consequences for patients with physical disability who are unable to see their doctor due to difficulty getting to the surgery. Improving access and meeting reasonable expectations for access and transport to and into primary care premises for patients with physical disability needs continued action from many, including:

- Increased collaboration between government departments (central and local), transport providers, the
NHS (including GPs), charities and patients to improve timely, affordable access from patients' homes to GP premises.

- Audits of the physical accessibility of primary care premises with improvements made where necessary, and consideration of newer, more accessible premises if necessary alterations are impractical;

- Continued advocacy efforts by physically disabled patients, and their representatives, in making their needs known.

Finally, despite the evidence from overseas cited above, there remains a significant gap in the literature investigating determinants of access to primary care for physically disabled patients in England, including 'attitudinal, expertise-related and systemic ${ }^{6}$ barriers. Evidence of such barriers is dominated by North American research. For example, a survey of rehabilitation clinic out-patients found barriers to primary care such as refusal to provide care, lack of accommodation for special needs when examination is needed (eg, by providing appropriate equipment, and/or assistance with transfer), and the patient needing to educate the clinician. ${ }^{36}$ A qualitative study of disabled patients who had reported healthcare access problems found evidence of poor attitudes of clinicians and other staff, including inadequate knowledge of, and training in, disability, over-focusing on the disability rather than the patient's current problem or preventative needs, and constraints on time. ${ }^{7}$ A survey conducted in the UK found that individuals with chronic health conditions or impairments were more likely to report problems with inexperienced or unhelpful staff, discrimination, anxiety or lack of confidence, lack of information and lack of help with communication. ${ }^{18}$ These and other practice-related factors, transport, costs, architecture and the support available to patients are also under-researched in England. Therefore, in addition to the practical actions outlined above, further quantitative and qualitative work is needed to help inform policy and practice to successfully improve access to English primary care for patients with physical disability.

Acknowledgements The authors acknowledge the work of the Department of Health, its academic advisers, and Ipsos MORI in conceiving, developing and performing the GPPS, and of all the patients who completed it. Particular thanks go to Professor Martin Roland of the Primary Care Unit of the Department of Public Health and Primary Care at the University of Cambridge for his involvement in study conception and enabling Visiting Researcher status for NTAP. NTAP also thanks Camille Maringe of the London School of Hygiene and Tropical Medicine (LSHTM) for reviewing initial plans for the study; Jacqueline Bell, also of LSHTM, for advising on appropriate use of survey commands in Stata; and Professor John Campbell of Exeter University for reviewing the manuscript.

Contributors NTAP conceived the final research question and aims and objectives, reviewed the literature, produced the analysis plan, undertook data preparation and manipulation specific to this study, performed the analyses and drafted the manuscript. GAA participated in study conception, reviewed the analysis plan, contributed to the analysis and critically reviewed the manuscript. BPDR contributed to decisions on the scope of analyses and critically reviewed the manuscript. All authors have approved the final version. 
Funding This research received no specific grant from any funding agency in the public, commercial or not-for-profit sectors.

Competing interests NTAP has a close family member with a long-standing physical disability.

Ethics approval This study was approved by the ethics committee of the London School of Hygiene and Tropical Medicine.

Provenance and peer review Not commissioned; externally peer reviewed.

Data sharing statement No additional data are available.

Open Access This is an Open Access article distributed in accordance with the Creative Commons Attribution Non Commercial (CC BY-NC 3.0) license, which permits others to distribute, remix, adapt, build upon this work noncommercially, and license their derivative works on different terms, provided the original work is properly cited and the use is non-commercial. See: http:// creativecommons.org/licenses/by-nc/3.0/

\section{REFERENCES}

1. World Health Organization. World Report on Disability 2011. Malta: World Health Organization, 2011. http://www.who.int/disabilities/ world report/2011/report.pdf

2. Office for Disability Issues. Disability prevalence fact sheet. Disability prevalence estimates 2010/11. London: Office for Disability Issues, 2012. http://odi.dwp.gov.uk/docs/res/factsheets/disability-prevalence. pdf (accessed Feb 2013).

3. Gunning N. Longstanding illness and personal care plans. In: Craig R, Hirani V, eds. Health Survey for England 2009. Volume 1. Health and lifestyles. London: The NHS Information Centre for Health and Social Care, 2010:19-35. https://catalogue.ic.nhs.uk/ publications/public-health/surveys/heal-surv-heal-life-eng-2009/ heal-surv-heal-life-eng-2009-rep-v2.pdf

4. World Health Organization. Disability and health. Fact sheet no. 352 2011. http://www who.int/mediacentre/factsheets/fs352/en/index.html (accessed Feb 2013)

5. Dejong G, Palsbo SE, Beatty PW, et al. The organization and financing of health services for persons with disabilities. Milbank $Q$ 2002;80:261-301.

6. McColl MA, Forster D, Shortt SED, et al. Physician experiences providing primary care to people with disabilities. Healthc Policy 2008;4:e129-47.

7. Scheer J, Kroll T, Neri MT, et al. Access barriers for persons with disabilities. The consumer's perspective. J Disabil Policy Stud 2003;13:221-30.

8. lezzoni LI, McCarthy EP, Davis RB, et al. Use of screening and preventive services among women with disabilities. Am J Med Qual 2001:16:135-44.

9. Morrison EH, George V, Mosqueda L. Primary care for adults with physical disabilities: perceptions from consumer and provider focus groups. Fam Med 2008;40:645-51.

10. Chaix B, Veugelers PJ, Boëlle P-Y, et al. Access to general practitioner services: the disabled elderly lag behind in underserved areas. Eur J Public Health 2005;15:282-7.

11. Huber M, Stanciole A, Wahlbeck K, et al. Quality in and equality of access to healthcare services. Brussels: European Commission, 2008. http://www.euro.centre.org/data/1237457784_41597.pdf

12. Van Brakel WH. Measuring health-related stigma-a literature review. Psychol Health Med 2006;11:307-34.

13. Lawthers AG, Pransky GS, Peterson LE, et al. Rethinking quality in the context of persons with disability. Int J Qual Health Care 2003;15:287-99.

14. United Nations. Convention on the Rights of Persons with Disabilities and Optional Protocol. New York: United Nations, 2006. http://www.un. org/disabilities/documents/convention/convoptprot-e.pdf.

15. Tomlinson M, Swartz L, Officer A, et al. Research priorities for health of people with disabilities: an expert opinion exercise. Lancet 2009;374:1857-62.

16. Great Britain. Equality Act 2010. (c.15). London: HMSO. http://www. legislation.gov.uk/ukpga/2010/15/pdfs/ukpga_20100015_en.pdf

17. Donnelly C, McColl MA, Charlifue S, et al. Utilization, access and satisfaction with primary care among people with spinal cord injuries: a comparison of three countries. Spinal Cord 2007;45:25-36.

18. Allerton L, Emerson E. British adults with chronic health conditions or impairments face significant barriers to accessing health services. Public Health 2012;126:920-27.
19. Ipsos MORI. The GP Patient Survey. [Online]. 2012. http://www. gp-patient.co.uk/ (accessed Feb 2013).

20. Ipsos MORI. Technical Annex for the GP Patient Survey. 2010/11 Annual Report. London: Ipsos MORI, 2011. http://gp-surveyproduction.s3.amazonaws.com/archive/2011/June/June $\% 202011 \%$ 20Technical\%20Annex.pdf

21. Ipsos MORI. Technical Annex for the GP Patient Survey. 2009/10 Annual Report. London: Ipsos MORI, 2010. http://gp-surveyproduction.s3.amazonaws.com/archive/2010/June/June\%202010\% 20Technical\%20Annex.pdf

22. Campbell J, Smith P, Nissen S, et al. The GP Patient Survey for use in primary care in the National Health Service in the UK-development and psychometric characteristics. BMC Fam Pr2009;10:57.

23. National Statistics. Census 2001. England Individual Form. Titchfield: National Statistics, 2001. http://www.ons.gov.uk/ons/ guide-method/census/census-2001/about-census-2001/ census-2001-forms/index.html

24. Office for National Statistics. Rural-Urban Definition (England and Wales). [Online]. 2009. http://www.ons.gov.uk/ons/guide-method/ geography/products/area-classifications/rural-urban-definition-and-la/ rural-urban-definition--england-and-wales-/index.html (accessed Nov 2013).

25. Noble M, McLennan D, Wilkinson $\mathrm{K}$, et al. The English Indices of Deprivation 2007. London: Department for Communities and Local Government, 2008. http://webarchive.nationalarchives.gov.uk/ 20100410180038/http://communities.gov.uk/documents/ communities/pdf/733520.pdf

26. Roland M, Elliott M, Lyratzopoulos G, et al. Reliability of patient responses in pay for performance schemes: analysis of national General Practitioner Patient Survey data in England. BMJ 2009;339: b3851.

27. Groves R. Nonresponse rates and nonresponse bias in household surveys. Public Opin Q 2006;70:646-75.

28. Bureau of the Census, US Department of Commerce. United States Census 2000. H. Disability and caregivers. Washington, DC: Bureau of the Census, 1998. http://www.census.gov/dmd/www/pdf/09h_di. pdf (accessed Nov 2013)

29. Central Statistics Office. National disability survey 2006: first results. Dublin: Stationery Office, 2008. http://www.cso.ie/en/media/csoie/ releasespublications/documents/otherreleases/nationaldisability/ National\%20Disability\%20Survey\%202006\%20First\%20Results\% 20full\%20report.pdf

30. Disability Rights Commission. Equal treatment: closing the gap. A formal investigation into physical health inequalities experienced by people with learning disabilities and/or mental health problems, 2006.

31. Anderson P, Kitchin R. Disability, space and sexuality: access to family planning services. Soc Sci Med 2000;51:1163-73.

32. Iezzoni LI, Davis RB, Soukup J, et al. Satisfaction with quality and access to health care among people with disabling conditions. Int $J$ Qual Health Care 2002;14:369-81.

33. Graham CL, Mann JR. Accessibility of primary care physician practice sites in South Carolina for people with disabilities. Disabil Health J 2008;1:209-14.

34. Castro SS, Cieza A, Cesar CL. Problems with accessibility to health services by persons with disabilities in Sao Paulo, Brazil. Disabil Rehabil 2011;33:1693-8.

35. Mudrick NR, Breslin ML, Liang M, et al. Physical accessibility in primary health care settings: results from California on-site reviews. Disabil Health J 2012;5:159-67.

36. Harrington AL, Hirsch MA, Hammond FM, et al. Assessment of primary care services and perceived barriers to care in persons with disabilities. Am J Phys Med Rehabil 2009;88:852-63.

37. Allen S, Mor V. The prevalence and consequence of unmet need. Contrasts between older and younger adults with disability. Med Care 1997;35:1135-48.

38. Iezzoni LI, Killeen MB, O'Day BL. Rural residents with disabilities confront substantial barriers to obtaining primary care. Health Serv Res 2006;41(4 Pt 1):1258-75.

39. Breeze E, Lang I. Physical functioning in a community context. In: Banks J, Breeze E, Lessof C, Nazroo J, eds. Living in the 21st Century: older people in England. The 2006 English Longitudinal Study of Ageing (Wave 3). London: The Institute for Fiscal Studies, 2008:57-117. http://www.ifs.org.uk/elsa/report08/ ch3.pdf

40. Department for Transport. Health-related travel difficulties. Personal travel factsheet-March 2010. London: Department for Transport, 2010. http://webarchive.nationalarchives.gov.uk/20100304070241/ http://www.dft.gov.uk/pgr/statistics/datatablespublications/personal/ ntsfactsheets/NTSHealthrelated.pdf (accessed Mar 2013). 